\section{Detection of deficiencies in immunoelectrophoretic patterns}

\author{
P. IRONSIDE ${ }^{1}$ From the Department of Pathology, \\ Monash University, Melbourne, Australia
}

When serum is examined by the usual immunoelectrophoretic technique an isolated deficiency may be overlooked due to the multiplicity of precipitin arcs and the confusion caused by overlapping arcs. To overcome these difficulties a simple method has been devised which takes advantage of the fact that antibody to a component which is not present in the test serum will diffuse beyond the region of the precipitin pattern and may be detected by reaction with a complete normal serum.

\section{MATERIALS AND METHODS}

Microscope slides ( 3 in. $\times 1$ in.) are covered by $2 \mathrm{ml}$ of $1.3 \%$ Ionagar $^{2}$ no. 2 in barbitone buffer, $p \mathrm{H} 8 \cdot 2, I=$ 0.025 . The wells and troughs are cut as shown in Figure 1. The wells are $1.3 \mathrm{~mm}$ in diameter and are separated from each other by $2.0 \mathrm{~mm}$. The troughs are $1.7 \mathrm{~mm}$ wide and each is separated from the nearest well by $2.5 \mathrm{~mm}$.

One well is filled with the test serum and the other well with a known normal serum. Migration of the samples takes at a constant current of $5 \mathrm{~mA}$ per slide for 65 minutes. The troughs are then filled with antiserum to whole human serum and diffusion proceeds for three days.

\section{RESULTS AND COMMENT}

The manner in which deficiencies are demonstrated is shown in Fig. 1, in which the test serum (in the lower well) is umbilical cord serum. This sample is deficient in orosomucoid, haptoglobin, and IgA and the antibodies to these proteins have diffused across the agar to react with the relevant proteins in the normal serum (upper well). The appearance produced is that of a displaced arc which is made conspicuous by its lack of symmetry with the normal pattern. The normal serum thus performs a dual function: its primary function is to detect antibody which has not reacted with the test serum but it also forms a normal pattern for comparison. Using the method deficiencies of caeruloplasmin (in Wilson's disease) and IgA have been demonstrated in patients' sera.

The success of the method depends on the particular antiserum used. One of the two antisera which were used failed to demonstrate caeruloplasmin deficiency even though it produced a caeruloplasmin arc with normal serum.

'Present address: Peter MacCallum Clinic, Melbourne, Australia.

${ }^{2}$ Oxoid Ltd., London, England.

Received for publication 28 June 1968.

\section{Loading starch gels using filter paper wicks}

G. PARKER LEWIS, W. J. MaCLENNAN, AND S. MILL®ึ From the University Medical Unit, Stobholl General Hospital, Glasgow.

Filter paper wicks are commonly used for loading proteitn samples into starch gels before electrophoresis. THJe usual procedure is to soak squares or strips of filter paper in the sample under examination and insert them iño slits previously made along the line of application. Edot wick is allowed to remain in the gel until electrophoresis is completed. We have examined this technique afpd Received for publication 28 June 1968.

Detection of deficiencies in immunoelectrophoretic patterns-concluded

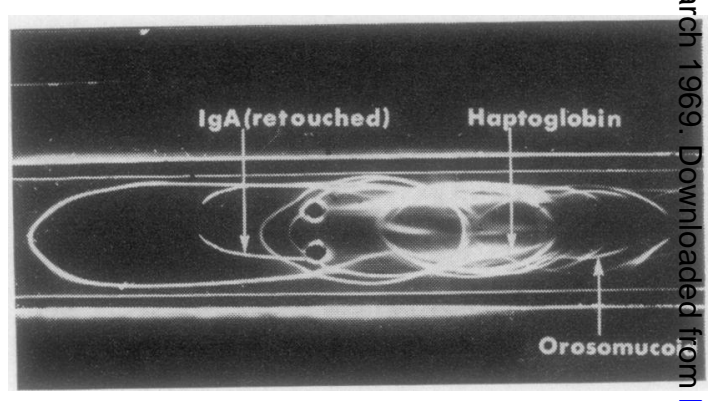

FIG. 1. The troughs contain horse antiserum againg whole human serum ${ }^{3}$. The uppar origin well contains normal adult serum. Deficiencies of orosomucoid, haptioglobin, and $\operatorname{IgA}$ in the umbilical cord serum in the lower well are shown by the three displaced arcs. The displaegd haptoglobin arc shows a reaction of identity with haptoglobin arc in the normal serum pattern.

That the method will detect an incomplete deficierey was shown by adding 1 part of normal serum to 3 parits of caeruloplasmin-deficient serum: a displaced caerutoplasmin arc was still obtained.

A method based on the same principle has been usf by Rabinovitz and Schen (1967) to detect $\beta_{1} \mathrm{a} / \mathrm{c}$ deficiengcy but in their method a deficiency is demonstrated bpa single arc whereas normal serum produces no arc.

I wish to thank Dr J. MacKenzie and Dr Kate Campbell for the abnormal sera, Professor R. C. Nairn and $\mathrm{Mr}$ H. A. Ward for helpful advice, and Miss Lana Tishler gor the photograph.

\section{REFERENCE}

Rabinovitz, M., and Schen, R. J. (1967). J. Pediat., 70, 617. ${ }^{3}$ Netherlands Red Cross Blood Transfusion Service, Amsterd的, The Netherlands. 
report modifications that have been found to increase substantially the quality of the electrophoretic patterns produced when sera are run in large starch gel blocks (7.25 in. $\times 4.0$ in. $\times 0.5$ in.), using a continuous borate system $p \mathrm{H} 8 \cdot 6$.

\section{PROCEDURE}

Utilizing capillary attraction Whatman no. $3 \mathrm{MM}$ filter paper squares $(0.4$ in.) are soaked with sera under test. Excess serum clinging to the trailing edge of each wick is gently removed with clean filter paper. They are then inserted into the starch gel along the line of application into previously cut slits, care being taken to handle the wicks very gently, using forceps with flattened, smooth grips. The upper edge of each wick is allowed to lie level or slightly below the surface of the gel. At this stage both submerged surfaces of each wick are carefully inspected for the presence of air bubbles. These must be removed by exerting slight pressure on the gel on each side of the wick. The gel is then subjected for precisely one hour to an electrophoretic current, twice that required under normal operative conditions $(8 \mathrm{~m}$ amps/1 in., cf $4 \mathrm{~m}$ amps/1 in. width). This causes proteins to enter the gel matrix. At the end of this time the current is switched off and the wicks removed. Electrophoresis is then continued under normal operative conditions for 16 to 20 hours.

\section{EQUALITY OF LOADING}

To make a quantitative comparison between protein fractions of different samples run in the same block, it is important that the volume of serum taken up by all the filter paper wicks is equal. The protein content was eluted from six sets (five in each) of standard wicks ( $0.4 \times 0.4 \mathrm{in}$.), each set being loaded with one of a series of human sera of total protein content within the range 5 and $6.5 \mathrm{~g} /$ $100 \mathrm{ml}$. The protein content of the eluate was measured, using the Lowry technique (Lowry, Rosebrough, Farr, and Randall, 1951). The quantity of protein, which can be equated with volume, taken up by each group of wicks was found to be adequately constant.

\section{ELECTROPHORETIC TRANSFER OF PROTEIN FROM WICK TO GEL}

Figure 1 shows the density of the electrophoretic patterns stained with Nigrosine of a single block in which the time allowed for transfer of the protein contained in a standard serum was graded from five minutes to 18 hours. Figure 2 shows the recovery of protein from the filter paper wicks following their removal from the gel at specific time intervals during the protein transfer period. It shows that the passage of protein into the gel occurs exponentially and is two thirds complete at one hour.

When filter paper wicks are used to load starch gel, their removal following the transfer of two thirds of the

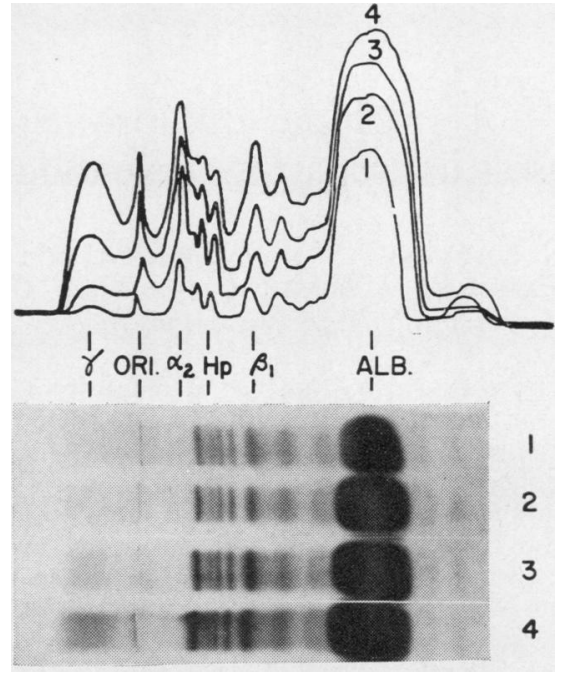

FIG. 1. The density of the electrophoretic patterns obtained when filter paper wicks loaded with a standard normal human serum are removed at five (1), 15 (2), 60 (3) minutes, and 18 hours (4) after the start of electrophoresis. The upper half of the figure compares the tracings obtained when the patterns were scanned by reflectance using a Chromoscan densitometer (Joyce, Loebl and Co., Inc.).

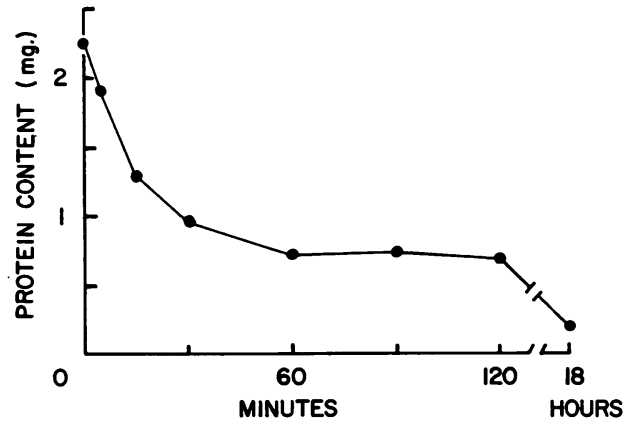

FIG. 2. The quantity of residual protein eluted from seven filter paper wicks after their removal from a starch gel block after electrophoresis for five, 15, 30, 60, 90, 120 minutes, and 18 hours.

proteins to the gel prevents trailing phenomena, a factor which can obscure the details of the alpha 2 and haptoglobin regions of the pattern.

\section{REFERENCE}

Lowry, O. H., Rosebrough, N. J., Farr, A. L., and Randall, R. J. (1951). J. biol. Chem., 193, 265. 